\title{
Maternal and infant genetic variants, maternal periconceptional use of selective serotonin reuptake inhibitors, and risk of congenital heart defects in offspring: population based study
}

\author{
Wendy N Nembhard, ${ }^{1}$ Xinyu Tang, ${ }^{2}$ Zhuopei Hu, ${ }^{2}$ Stewart MacLeod, ${ }^{1}$ Zachary Stowe,, ${ }^{3}$ Daniel Webber,
}

${ }^{1}$ Division of Birth Defects Research, Department of

Pediatrics, College of Medicine, University of Arkansas for

Medical Sciences and Arkansas Children's Research Institute, Little Rock, AR, 72202, USA

2Division of Biostatistics, Department of Pediatrics,

College of Medicine, University of Arkansas for Medical

Sciences, Arkansas Children's

Research Institute, Little Rock, AR, 72202 USA

3Department of Psychiatry, College of Medicine, University of Arkansas for Medical Sciences, Little Rock, Arkansas, 72205, USA

Correspondence to: W Nembhard wnnembhard@uams.edu

Cite this as: $B M J$ 2017;356:j832

http://dx.doi.org/10.1136/bmj.j832

Accepted: 27 January 2017

\section{ABSTRACT}

OBJECTIVE

To evaluate whether the association between maternal periconceptional use of selective serotonin reuptake inhibitors (SSRIs) and increased risk of congenital heart defects in offspring is modified by maternal or infant genetic variants in folate, homocysteine, or transsulfuration pathways.

\section{DESIGN}

Population based study. DNA from mothers, fathers, and infants was genotyped with an Illumina

GoldenGate custom single nucleotide polymorphism panel. A hybrid design based on a log linear model was used to calculate relative risks and Bayesian false discovery probabilities (BFDP) to identify polymorphisms associated with congenital heart defects modified by SSRI use.

\section{DATA SOURCES}

Data from the US National Birth Defects Prevention Study on 1180 liveborn infants with congenital heart defects and 1644 controls, born 1997-2008.

\section{MAIN OUTCOME MEASURES}

Cases included infants with selected congenital heart defects and control infants had no major defects. SSRI use was obtained from telephone interviews with mothers.

RESULTS

For women who reported taking SSRIs

periconceptionally, maternal SHMT1 (rs9909104) GG and $A G$ genotypes were associated with a 5.9 and 2.4 increased risk of select congenital heart defects in offspring, respectively, versus the AA genotype $(B F D P=0.69)$. Compared with the AA genotype, BHMT

\section{WHAT IS ALREADY KNOWN ON THIS TOPIC}

Epidemiologic studies have produced inconsistent results regarding the impact of the maternal use of SSRIs during embryogenesis on congenital heart defects

These inconsistent results could be a consequence of a complex relation between competing risk factors, behaviors, and metabolic pathways for both mental illness and congenital heart defects

Low serum or red blood cell folate and/or raised homocysteine concentrations are associated with an increased risk of both congenital heart defects and depression; whereas folate supplementation could lower the risk, diminish depressive symptoms, and overcome drug resistant depression

\section{WHAT THIS STUDY ADDS}

Common allelic variants in maternal and infant genes involved in the folate, homocysteine, and glutathione/transulfuration metabolic pathways can modify the association between maternal periconceptional use of SSRIs and risk of congenital heart defects

(rs492842 and rs542852) GG and AG genotypes were associated with twice the risk of congenital heart defects (BFDP $=0.74$ and 0.79 , respectively). MGST1 (rs2075237) CC and AC genotypes were associated with an increased risk compared with the GG genotype (8.0 and 2.8 , respectively; $B F D P=0.79$ ). Single nucleotide polymorphism in infant genes in the folate (MTHFS rs12438477), homocysteine (TRDMT1 rs6602178 and GNMT rs11752813) and transsulfuration (GSTP1 rs7941395 and MGST1 rs7294985) pathways were also associated with an increased risk of congenital heart defects.

\section{CONCLUSIONS}

Common maternal or infant genetic variants in folate, homocysteine, or transsulfuration pathways are associated with an increased risk of certain congenital heart defects among children of women taking SSRIs during cardiogenesis.

\section{Introduction}

In the US the prevalence of depression is high in women of childbearing age. ${ }^{1}$ The prevalence of clinical antenatal depression is $10-15 \%,{ }^{2}$ and $8-13 \%$ of pregnant women are prescribed antidepressant drugs. ${ }^{3-6}$ Serotonin selective reuptake inhibitors (SSRIs) are the most common class of antidepressants prescribed during pregnancy. ${ }^{357}$ Their effectiveness is attributed, in part, to their ability to increase the post-synaptic availability of the neurotransmitter serotonin by inhibiting the serotonin (5-HT) transporter (SERT or 5-HTT), resulting in reduced symptoms of depression among many patients. ${ }^{8-12}$ - -HT is also a vital signaling molecule in cardiogenesis. Consequently, if present during cardiogenesis, SSRIs could interfere with 5-HT signaling, resulting in several different types of congenital heart defects. ${ }^{911}$ Infants with such defects have an increased risk of morbidity and mortality. ${ }^{13-17}$

Epidemiologic studies have produced inconsistent results regarding the impact of maternal use of SSRIs during embryogenesis. Some studies have reported an increased risk of congenital heart defects, ${ }^{18-22}$ while others report no association. ${ }^{1823-32}$ Some publications implicate paroxetine $\mathrm{e}^{2533-37}$ and fluoxetine ${ }^{2638}$ as specific SSRIs that are most teratogenic for congenital heart defects, while others do not. ${ }^{1819232426353639}$ These inconsistent results could be a consequence of a complex relation between similar risk factors, genetics, behaviors, and metabolic pathways for both mental illness and congenital heart defects. Women are prescribed SSRIs for various illnesses, including but not limited to depression, panic disorder, and obsessive compulsive disorder. These psychiatric conditions are associated with poorer 
health behaviors and obstetric outcomes. For example, women diagnosed with depression are more likely than the general population to have concomitant behaviors and health conditions independently associated with an increased risk of congenital heart defects, including prenatal cigarette smoking, alcohol and/or illicit drug use, poor diet, ${ }^{25}$ 40-44 use of other prescription drugs, being overweight/obese, and having diabetes and hypertension. ${ }^{825} 40$ 45-50 Moreover, low serum or red blood cell folate $^{5152}$ and/or raised homocysteine concentrations ${ }^{53-55}$ are associated with an increased risk of both congenital heart defects and depression ${ }^{56-59}$; whereas, folate supplementation could lower the risk of congenital heart defects, ${ }^{60-63}$ diminish depressive symptoms, ${ }^{10}{ }^{12}$ and overcome drug resistant depression. ${ }^{1264-66}$ Polymorphisms in genes involved in the folate metabolic pathway are also associated with an increased risk of congenital heart defects ${ }^{5367-69}$ and depression..$^{70-72}$

Three metabolic pathways implicated in an increased risk of congenital heart defects-folate, homocysteine, and glutathione/transsulfuration pathways-could be related to pathways involved in synthesis of serotonin and other important neurotransmitters that influence depression. L-methylfolate, the biologically active form of folate, regulates the formation of tetrahydrobiopterin (BH4), which is involved in the synthesis of the neurotransmitters, serotonin, dopamine, and norepinephrine. ${ }^{1012}$ Because of the potential interplay between folate, homocysteine, depression, and congenital heart defects, we hypothesized that the impact of SSRIs on cardiogenesis could be modulated by common maternal or infant genetic variants in folate and homocysteine related pathways. Thus, it is plausible that maternal or infant genetic variants within these pathways augment the adverse effects of SSRIs if key protein or enzyme production is inhibited or amplified. We examined the potential impact of common allelic variants in maternal and infant genes involved in the folate, homocysteine, and glutathione/transsulfuration metabolic pathways on the association between maternal periconceptional use of SSRIs and risk of congenital heart defects in their offspring.

\section{Methods}

We tested our hypothesis with a case control design using data from the National Birth Defects Prevention Study (NBDPS). This was the largest population based case control study conducted in the US and was designed to investigate the contribution of genetic, environmental, and behavioral factors to the occurrence of major non-syndromic birth defects. ${ }^{7374}$ Briefly, families with affected children (cases) and control families were identified from population based birth defects surveillance systems in 10 US states, specifically Arkansas, California, Georgia, Iowa, Massachusetts, New Jersey, New York, North Carolina, Texas, and Utah. The study enrolled non-Hispanic white, non-Hispanic black, Hispanic, and Asian women and their families. Our analysis included non-Hispanic white, non-Hispanic black, and Hispanic families of infants with estimated dates of delivery from October 1997 to August 2008.
Our study population consisted of 1180 case families with singleton liveborn infants with a diagnosis of a conotruncal or right or left obstructive heart defect within the first year of life and 1644 control families with singleton liveborn infants without any diagnosed major structural birth defect who provided a genetic sample. Infants with congenital heart defects affected by a known single gene disorder, chromosomal abnormality, or syndrome were excluded. In each surveillance program, trained staff abstracted medical records and actively ascertained cases from hospitals, birthing centers, and other medical facilities. For NBDPS, controls were randomly selected (one control to three cases) by each program from the same underlying population area as case infants from birth certificate records or hospital discharge logs. The number of controls selected each month for the overall study was proportionate to the number of births in the same month in the prior year. ${ }^{74}$

\section{Ascertainment of infants with congenital heart defects}

Cases were identified based on the infant having at least one of the following diagnostic procedures: echocardiograms, surgical reports, cardiac catheterizations, or autopsies. A pediatric cardiologist at each study center then reviewed all information on diagnostic procedures to ensure uniform criteria for diagnoses. Classification of congenital heart defects was done centrally by pediatric cardiologists, using the classification system specifically developed for the NBDPS, which incorporates cardiac phenotype, cardiac complexity, and extracardiac anomalies. ${ }^{75}$ In our study, conotruncal defects included truncus arteriosus, interrupted aortic arch type $\mathrm{B}$, transposition of the great arteries, double outlet right ventricle, conoventricular septal defects, tetralogy of Fallot, and pulmonary atresia with ventricular septal defect. ${ }^{75}$ Obstructive heart defects (left or right) included hypoplastic left heart syndrome, tricuspid atresia, pulmonary valve atresia, coarctation of the aorta, interrupted aortic arch types $\mathrm{A}$ and $\mathrm{C}$, aortic stenosis, pulmonary valve stenosis, and Ebstein's anomaly. ${ }^{75}$

\section{Ascertainment of maternal use of SSRIs}

After they had given informed consent, mothers of affected children and controls completed a one hour computer assisted telephone interview administered in English or Spanish. ${ }^{7376}$ During the interview, women were asked about periconceptional (that is, one month before conception through to three months after conception of the index pregnancy) folic acid supplementation and maternal drug use. For our study, we defined periconceptional folic acid supplementation as use for at least two months during the exposure window. SSRI use was defined as any use of the following medications: fluoxetine (Sarafem, Prozac, Prozac Weekly, Selfemra, Rapiflux), fluvoxamine (Luvox, Luvox CR), paroxetine (Pexeva, Brisdelle, Paxil, Paxil CR), escitalopram (Lexapro), citalopram (Celexa), sertraline (Zoloft), and vortioxetine (Brintellix), for any indication during the periconception period. 


\section{DNA sample collection}

After completing the maternal telephone interview, case and control families were mailed buccal swab kits for collection of maternal, infant, and paternal DNA samples. ${ }^{7376}$ DNA sample storage and processing methods for the NBDPS have been described in detail elsewhere. ${ }^{7677}$ We included all cases and controls who had DNA samples available (mother, infant, and father, or any paired combination).

\section{Genotyping and quality control}

We selected a custom panel of 1536 single nucleotide polymorphisms from 62 genes involved in the folate, homocysteine, and glutathione/transsulfuration metabolic pathways or DNA synthesis/repair for analysis. ${ }^{78}$ We performed genotyping using $200 \mathrm{ng}$ of whole genome amplified DNA on Illumina's customizable GoldenGate platform. ${ }^{79}$ We uses Puregene DNA purification reagents (Qiagen, Valencia CA) to extract DAN from buccal brush samples. The resultant genomic DNA was quantified with TaqMan RNase P Detection Reagents Kit (Life Technologies, ThermoFisher) and a standard curve of DNA of known DNA concentration.

Genomic DNA extracted from buccal samples was subjected to whole genome amplification. Briefly, 10-15 ng of genomic DNA was amplified with the GenomePlex kit (Sigm Chemical, Saint Louis MO) according to the manufacturer's protocol. The whole genome amplified product was quantified by the TaqMan RNase P Detection Reagents Kit, and $200 \mathrm{ng}$ was used as input DNA for the Illumina Golden Gate assay. The performance of whole genome amplified DNA in microarray analysis was previously demonstrated by Cunningham and colleagues. ${ }^{80}$

Initial genotyping calls were generated with GenCall, Illumina's proprietary algorithm. We found that the quality of genotype clustering varied substantially from one single nucleotide polymorphism to another on the GoldenGate custom platform, whether we used blood or buccal samples. We therefore developed SNPMClust, a bivariate Gaussian model based genotype calling algorithm to complement the default Illumina GenCall algorithm and applied strict quality control measures. ${ }^{81} \mathrm{We}$ tested this method in a pilot study (described in detail by Hobbs and colleagues ${ }^{68}$ ) on blood and buccal samples from 94 women. We found a $99.2 \%$ concordance rate between whole genome amplified buccal DNA and blood derived DNA among genotype calls and are therefore confident in the genotypes we used.

We genotyped 6416 individual samples and removed 576 samples from analysis because of study ineligibility, low genotype call rates, or high rates of Mendelian inconsistency, resulting in an analytic sample consisting of 5840 individuals from 1180 case and 1644 control families. To ensure high quality genetic data, we applied stringent quality control criteria and excluded single nucleotide polymorphisms with obviously poor clustering behavior, no call rates $>10 \%$, Mendelian error rates $>5 \%$, minor allele frequencies $<5 \%$, or significant deviation from Hardy-Weinberg equilibrium in at least one racial group $\left(\mathrm{P}<10^{-4}\right)$. After the quality assessment, the analytical data had 872 variants in total.

\section{Statistical methods}

We calculated summary statistics for main study variables: means with standard deviations for continuous variables and frequencies with percentages for categorical variables. We compared the distributions of continuous variables between cases and controls using independent two sample $t$ tests and the proportions of categorical variables using $\chi^{2}$ tests. Log linear models based on the hybrid design ${ }^{82}$ were used for analysis as we genotyped both triads of case-parents and control-parents; this method is the most optimal and appropriate statistical approach. ${ }^{82}$ The log linear model was fitted for each single nucleotide polymorphism as a function of: mating types (three possible genotypes for each parent); the interaction between mating types and SSRI exposure; disease status (case/ control); maternal genotypes; infant genotypes; the interaction between disease status and maternal genotypes; the interaction between disease status and infant genotypes; the interaction between disease status, maternal genotypes, and SSRI exposure; and the interaction between disease status, infant genotypes, and SSRI exposure. This model specification assessed the interaction between maternal genotype and SSRI exposure and the interaction between infant genotype and SSRI exposure. We assumed a log additive model (multiplicative risk of alleles), in which the genotype was coded as 0,1 , and 2, indicating zero, one, and two copies of the minor allele. Under this assumption, the relative risk of carrying two copies of the allele is the square of the relative risk of carrying one copy of the same allele, with zero copies as the reference.

We also calculated the Bayesian false discovery probability (BFDP) 83 for the interaction between maternal genotype and SSRI exposure and the interaction between infant genotype and SSRI exposure using the interaction estimates from the log linear models. This probability balances the relative cost between a false negative and a false positive finding; in the results section, we report associations where probability $<0.8$ and $95 \%$ confidence intervals where $\alpha=0.05$. Probability $<0.8$ is widely used to indicate noteworthy findings in candidate gene based association studies with strong prior knowledge that the selected genes are likely to be associated with the disease. ${ }^{84-86}$ We used statistical software R v3.1.0 (R Foundation for Statistical Computing, Vienna) for computing summary statistics, performing tests, and calculating Bayesian false discovery probabilities. LEM $^{87}$ statistical software was used to fit log linear models with incomplete family genotype data by using the expectation maximization algorithm. ${ }^{88-90}$

\section{Patient involvement}

The research question and outcome measures were not informed by participant priorities, experiences, or preferences. Participants were not involved in the design, recruitment process, or conduct of this study. Findings from this study and all publications that use NBDPS data are available to participants on www.nbdps.org. 


\section{Results}

Of 1180 affected infants (cases), 616 had conotruncal defects and 569 had obstructive heart defects. There were no significant differences in sociodemographic or maternal periconceptional characteristics between cases and controls, including folic acid supplementation and prenatal maternal cigarette smoking (tables 1 and 2), with the exception of maternal body mass index (BMI). Case mothers were more likely to be overweight and obese than control mothers $(\mathrm{P}<0.002)$. Overall the prevalence of SSRI use during the periconceptional period was relatively low. Only $5 \%$ of case and 3\% of control mothers reported SSRI use during the relevant period, but the difference was significant $(\mathrm{P}<0.04)$. The prevalence of SSRI use did not differ between mothers of infants with a conotruncal or obstructive heart

\begin{tabular}{|c|c|c|c|}
\hline Maternal characteristics & Cases $(n=1180)$ & Control $(n=1644)$ & Pvalue* \\
\hline Mean (SD) maternal age at delivery & $28(6.1)$ & $27(6.0)$ & $<0.001$ \\
\hline \multicolumn{4}{|l|}{ Maternal race/ethnicity: } \\
\hline Non-Hispanic white & $814(69)$ & $1135(69)$ & \multirow{5}{*}{0.70} \\
\hline Non-Hispanic black & $110(9)$ & $144(9)$ & \\
\hline Hispanic & $189(16)$ & $286(17)$ & \\
\hline Other & $63(5)$ & $79(5)$ & \\
\hline Missing & 4 & 0 & \\
\hline \multicolumn{4}{|l|}{ Maternal education: } \\
\hline$<12$ years & $156(13)$ & 217 (13) & \multirow{5}{*}{0.57} \\
\hline High school diploma or equivalent & $306(26)$ & $412(25)$ & \\
\hline$<4$ years of college education & $343(29)$ & $454(28)$ & \\
\hline$\geq 4$ years of college or degree & $372(32)$ & $559(34)$ & \\
\hline Missing & 3 & 2 & \\
\hline \multicolumn{4}{|l|}{ Mean household income (\$): } \\
\hline$<10000$ & $164(15)$ & $236(15)$ & \multirow{5}{*}{0.85} \\
\hline $10000-299999$ & $313(28)$ & $408(27)$ & \\
\hline $30000-49999$ & $247(22)$ & $348(23)$ & \\
\hline$\geq 50000$ & $397(35)$ & $539(35)$ & \\
\hline Missing & 59 & 113 & \\
\hline \multicolumn{4}{|l|}{ Maternal BMI: } \\
\hline Underweight $(<18.5)$ & $45(4)$ & $74(5)$ & \multirow{5}{*}{0.002} \\
\hline Normal weight $(18.5-<25.0)$ & $555(49)$ & $878(55)$ & \\
\hline Overweight $(25.0-<30.0)$ & $288(25)$ & $361(23)$ & \\
\hline Obese $(\geq 30.0)$ & $251(22)$ & $281(18)$ & \\
\hline Missing & 41 & 50 & \\
\hline \multicolumn{4}{|l|}{ Maternal SSRI use during pregnancy: } \\
\hline Yes & $57(5)$ & $54(3)$ & \multirow{2}{*}{0.04} \\
\hline No & $1119(95)$ & $1590(97)$ & \\
\hline \multicolumn{4}{|c|}{ Periconceptional folic acid supplementation: } \\
\hline Yes & $642(55)$ & $912(55)$ & \multirow{3}{*}{0.62} \\
\hline No & $535(45)$ & $732(45)$ & \\
\hline Missing & 3 & 0 & \\
\hline \multicolumn{4}{|l|}{ Alcohol consumption during pregnancy: } \\
\hline Yes & $264(23)$ & $390(24)$ & \multirow{3}{*}{0.46} \\
\hline No & $905(77)$ & $1250(76)$ & \\
\hline Missing & 11 & 4 & \\
\hline \multicolumn{4}{|l|}{ Cigarette smoking during pregnancy: } \\
\hline Yes & $190(16)$ & $287(17)$ & \multirow{3}{*}{0.36} \\
\hline No & $986(84)$ & $1356(83)$ & \\
\hline Missing & 4 & 1 & \\
\hline
\end{tabular}

defect. The SSRIs most commonly taken during the periconception period by women in our study were sertraline $(38.7 \%)$, fluoxetine $(27.0 \%)$, and paroxetine $(21.6 \%)$. No one reported using fluvoxamine or vortioxetine (table 3).

\section{Maternal genotype and risk of congenital heart defects}

We included 872 single nucleotide polymorphisms within 60 genes in the final analyses. There was a significant (BFDP <0.8) increased risk of congenital heart defects for maternal genotypes for four single nucleotide polymorphisms in three genes-serine hydroxymethyltransferase 1 (soluble) (SHMT1), betaine-homocysteine S-methyltransferase (BHMT), and microsomal glutathione S-transferase 1 (MGST1)among women taking SSRIs during the periconceptional period (table 4). Overall, the risk of having an infant with a congenital heart defect was higher for women with homozygous minor alleles than for women with only one copy of the minor allele. Among women reporting periconceptional use of SSRIs during pregnancy, those who had one or two minor allele (G) copies of rs9909104 in SHMT1 had increased risks of congenital heart defects in offspring compared with exposed women who carried no copies (relative risk 2.43 (95\% confidence interval 1.46 to 4.03) and 5.90 (2.13 to 16.24), respectively). SSRI users who were heterozygous (AG allele) for two single nucleotide polymorphisms on the BHMT gene had an increased risk of a congenital heart defect if they took SSRIs during the periconception period (2.15 (1.33 to 3.46) for rs492842 and 2.06 (1.26 to 3.34) for rs542852) compared with women who did not take SSRIs during the periconception period and had the AA allele. SSRI users who were homozygous for the $G$ allele of the rs492842 and the rs542852 single nucleotide polymorphisms had over four times the risk of having an affected child (4.62, 1.77 to 11.97). The greatest risk of having an affected child was found in women who took SSRIs during the periconception period and had the CC and AC alleles for rs2075237 on gene MGST1 (7.95 (2.50 to 25.40 ) and 2.82 (1.58 to 5.04), respectively) compared with women who had the AA allele.

Infant genotypes and risk of congenital heart defect We also observed a significant increased risk of congenital heart defects for infant genotypes (table 4). We observed increased risk in three single nucleotide polymorphisms in three genes involved in the transsulfuration pathway: 0-6-methylguanine-DNA methyltransferase (MGMT), glutathione S-transferase pi (GSTP1), and microsomal glutathione S-transferase 1 (MGST1). Infants who had the AG allele in single nucleotide polymorphisms rs11511217 on gene MGMT, rs7941395 on GSTP1, and rs7294985 on MGST1 also had increased risk of congenital heart defects if their mothers took SSRIs during the periconceptional period (relative risks 2.41 (95\% confidence interval 1.45 to 4.01 ), 2.17 (1.38 to 3.41), and 2.47 (1.45 to 4.21), respectively). Infants with periconceptional exposure to SSRIs who had the GG allele on the same single nucleotide 


\begin{tabular}{|c|c|c|c|c|c|c|}
\hline \multirow[b]{2}{*}{ Maternal characteristics } & \multicolumn{3}{|c|}{ SSRI users } & \multicolumn{3}{|c|}{ SSRI non-users } \\
\hline & Cases & Control & Pvalue* & Cases & Control & $P$ value* \\
\hline No of women & 57 & 54 & - & 1119 & 1590 & - \\
\hline Mean (SD) maternal age at delivery & $29(5.5)$ & $29(5.7)$ & 0.94 & $28(6.2)$ & $27(6)$ & $<0.001$ \\
\hline \multicolumn{7}{|l|}{ Maternal race/ethnicity: } \\
\hline African American & $3(5)$ & $3(6)$ & \multirow{5}{*}{0.57} & $107(10)$ & $141(9)$ & \multirow{5}{*}{0.82} \\
\hline White & $48(84)$ & $46(85)$ & & $765(68)$ & $1089(68)$ & \\
\hline Hispanic & $2(4)$ & $4(7)$ & & $187(17)$ & $282(18)$ & \\
\hline Others & $4(7)$ & $1(2)$ & & $59(5)$ & $78(5)$ & \\
\hline Missing & 0 & 0 & & 1 & 0 & \\
\hline \multicolumn{7}{|l|}{ Maternal education: } \\
\hline$<12$ years & $6(11)$ & $4(7)$ & \multirow{5}{*}{0.51} & $150(13)$ & $213(13)$ & \multirow{5}{*}{0.74} \\
\hline High school degree or equivalent & $14(25)$ & $14(26)$ & & $291(26)$ & $398(25)$ & \\
\hline $1-3$ years of college & $25(44)$ & $19(35)$ & & $318(28)$ & $435(27)$ & \\
\hline$\geq 4$ years of college or degree & $12(21)$ & $17(31)$ & & $360(32)$ & $542(34)$ & \\
\hline Missing & 0 & 0 & & 0 & 2 & \\
\hline \multicolumn{7}{|l|}{ Mean household income (\$): } \\
\hline$<10000$ & $4(7)$ & $8(15)$ & \multirow{5}{*}{0.61} & $160(15)$ & $228(15)$ & \multirow{5}{*}{0.89} \\
\hline $10000-\leq 29999$ & $21(38)$ & $10(19)$ & & $291(27)$ & $398(27)$ & \\
\hline $30000-\leq 49000$ & $17(30)$ & $13(24)$ & & $230(22)$ & $335(23)$ & \\
\hline$\geq 50000$ & $14(25)$ & $23(43)$ & & $383(36)$ & $516(35)$ & \\
\hline Missing & 1 & 0 & & 55 & 113 & \\
\hline \multicolumn{7}{|l|}{ Maternal BMI: } \\
\hline Underweight (BMI <18.5) & $1(2)$ & $3(6)$ & \multirow{5}{*}{0.06} & $44(4)$ & $71(5)$ & \multirow{5}{*}{0.01} \\
\hline Normal weight $(18.5-<25)$ & $23(41)$ & $28(52)$ & & $531(49)$ & $850(55)$ & \\
\hline Overweight $(25-<30)$ & $9(16)$ & $13(24)$ & & $279(26)$ & $348(23)$ & \\
\hline Obese $(\geq 30)$ & $23(41)$ & $10(19)$ & & $228(21)$ & $271(18)$ & \\
\hline Missing & 1 & 0 & & 37 & 50 & \\
\hline \multicolumn{7}{|c|}{ Periconceptional folic acid supplementation: } \\
\hline Yes & $30(53)$ & $41(76)$ & \multirow{2}{*}{0.02} & $611(55)$ & $871(55)$ & \multirow{2}{*}{0.94} \\
\hline No & $27(47)$ & $13(24)$ & & $508(45)$ & $719(47)$ & \\
\hline \multicolumn{7}{|l|}{ Alcohol consumption during pregnancy: } \\
\hline Yes & $13(23)$ & $15(28)$ & \multirow{3}{*}{0.66} & $251(23)$ & $375(24)$ & \multirow{3}{*}{0.55} \\
\hline No & $44(77)$ & $39(72)$ & & $860(77)$ & $1211(76)$ & \\
\hline Missing & 0 & 0 & & 8 & 4 & \\
\hline \multicolumn{7}{|l|}{ Cigarette smoking during pregnancy: } \\
\hline Yes & $15(26)$ & $10(19)$ & \multirow{3}{*}{0.64} & $175(16)$ & $277(17)$ & \multirow{3}{*}{0.23} \\
\hline No & $42(74)$ & $44(81)$ & & $943(84)$ & $1312(83)$ & \\
\hline Missing & 0 & 0 & & 1 & 1 & \\
\hline
\end{tabular}

polymorphisms had increased risks of congenital heart defects, ranging from 4.71 to 6.10 . The greatest risk for having an infant with a congenital heart defect occurred in women who took SSRIs during the periconception period and had an infant with the AA and AC alleles for rs12438477 on 5,10-methenyltetrahydrofolate synthetase (MTHFS) gene (6.76 (2.56 to 17.89) and 2.60 (1.60 to 4.23), respectively) compared with an exposed infant with the CC allele. Increased risks of congenital heart defects were also seen in infants with variants in single nucleotide polymorphisms in two genes involved in the homocysteine pathway, tRNA aspartic acid methyltransferase 1 (TRDMT1) and glycine $\mathrm{N}$-methyltransferase (GNMT). Women had about twice the risk of having an infant with a congenital heart defect if she was exposed to a periconceptional SSRI

\begin{tabular}{|c|c|c|c|c|c|c|c|c|c|c|c|c|c|c|c|}
\hline \multirow[b]{2}{*}{ Type of SSRI } & \multicolumn{5}{|c|}{$\begin{array}{l}\text { Mothers }(n=57) \text { of infants with congenital heart } \\
\text { defects }(n=1180) \text { by month of pregnancy }\end{array}$} & \multicolumn{5}{|c|}{$\begin{array}{l}\text { Mothers }(n=54) \text { of control infants ( } n=1644) \text { by } \\
\text { month of pregnancy }\end{array}$} & \multicolumn{5}{|c|}{ Total $(n=111)$ by month of pregnancy } \\
\hline & Before & 1st & 2nd & $3 r d$ & Total & Before & 1 st & 2nd & $3 r d$ & Total & Before & 1 st & 2nd & $3 r d$ & Total* \\
\hline Sertraline & $15(13.5)$ & $18(16.2)$ & $14(12.6)$ & $14(12.6)$ & $23(20.7)$ & $17(15.3)$ & $16(14.4)$ & $15(13.5)$ & $14(12.6)$ & $20(18.0)$ & $32(28.8)$ & $34(30.6)$ & $29(26.1)$ & $28(25.2)$ & $43(38.7)$ \\
\hline Fluoxetine & $12(10.8)$ & $10(9.0)$ & $9(8.1)$ & $7(6.3)$ & $13(11.7)$ & $14(12.6)$ & $14(12.6)$ & $11(9.9)$ & $9(8.1)$ & $17(15.3)$ & $26(23.4)$ & $24(21.6)$ & $20(18.0)$ & $16(14.4)$ & $30(27.0)$ \\
\hline Paroxetine & $10(9.0)$ & $8(7.2)$ & $6(5.4)$ & $6(5.4)$ & $10(9.0)$ & $13(11.7)$ & $14(12.6)$ & $13(11.7)$ & $12(10.8)$ & $14(12.6)$ & $23(20.7)$ & $22(19.8)$ & 19 (17.1) & $18(16.2)$ & $24(21.6)$ \\
\hline Citalopram & $10(9.0)$ & $9(8.1)$ & $2(1.8)$ & $2(1.8)$ & $10(9.0)$ & $4(3.6)$ & $4(3.6)$ & $3(2.7)$ & $3(2.7)$ & $4(3.6)$ & $14(12.6)$ & $13(11.7)$ & $5(4.5)$ & $5(4.5)$ & $14(12.6)$ \\
\hline Escitalopram & $5(4.5)$ & $5(4.5)$ & $4(3.6)$ & $2(1.8)$ & $5(4.5)$ & $4(3.6)$ & $5(4.5)$ & $3(2.7)$ & $3(2.7)$ & $5(4.5)$ & $9(8.1)$ & $10(9.0)$ & $7(6.3)$ & $5(4.5)$ & $10(9.0)$ \\
\hline
\end{tabular}

${ }^{*}$ Total does not equal 111 as some women used more than one type of SSRI. 


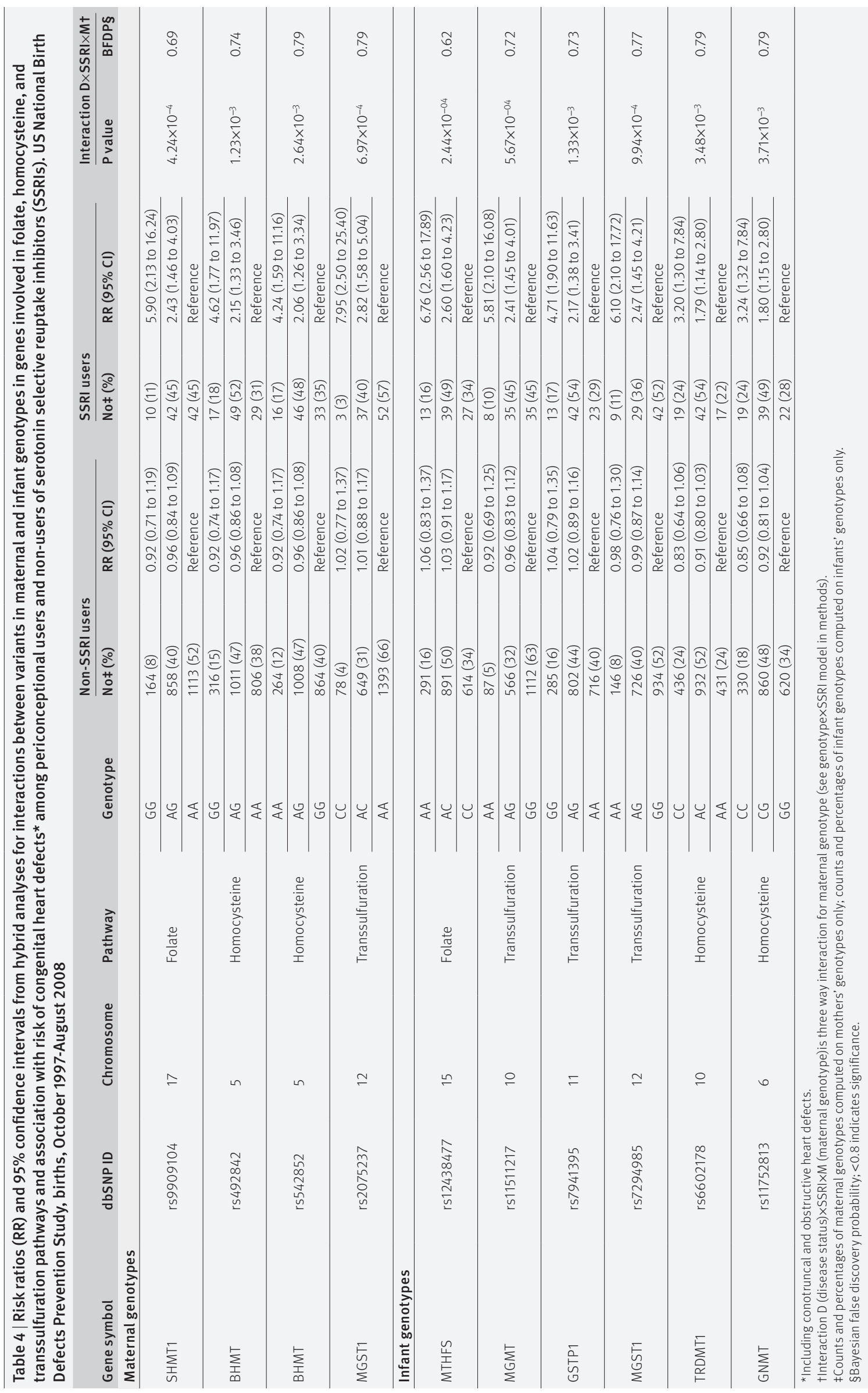

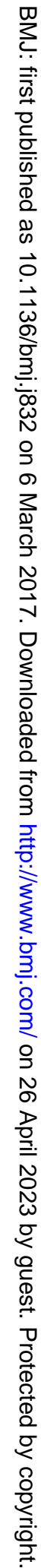




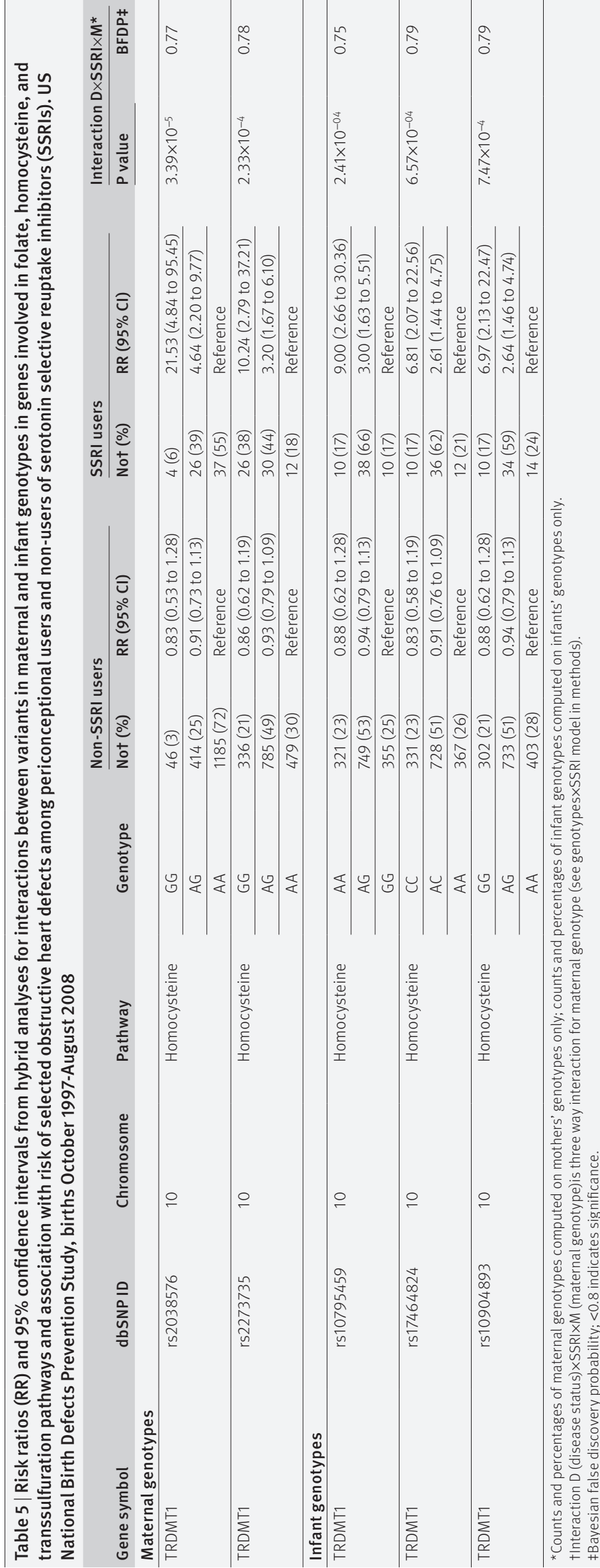

and had an infant with the allele AC on single nucleotide polymorphism rs66022178 in the TRDMT1 gene or the CG allele on single nucleotide polymorphism rs11752813 in the GNMT gene (1.79 (1.14 to 2.80) and 1.80 (1.15 to 2.80), respectively). For both single nucleotide polymorphisms in the respective genes, the risks were 3.2 (1.30 to 7.84 and 1.32 to 7.84 ) for the CC alleles.

\section{Subgroup analysis}

We conducted subanalyses to determine whether risk varied by subgroup of congenital heart defect (table 5). We did not find any significant risk ratios among conotruncal heart defects (as determined by BFDP) but did find increased risk by maternal and infant genotype for obstructive heart defects among periconceptional SSRI users. The risk was evident only for single nucleotide polymorphisms on the TRDMT1 gene. The risk ratio for women who took an SSRI during the periconception period and had the AG or GG genotype for polymorphism rs2038576 in the TRDMT1 gene was 4.64 (95\% confidence interval 2.20 to 9.77) and 21.53 (4.84 to 95.45), respectively) compared with exposed women with the AA genotype. For women taking SSRIs during the periconception period with the AG or GG genotype for polymorphism rs2273735 in the TRDMT1 gene the relative risks were 3.20 (1.67 to 6.10) and 10.24 (2.79 to 37.21) compared with women with the AA genotype exposed to SSRIs.

Similar to our findings for maternal genotypes, increased risk was observed only for single nucleotide polymorphisms in the TRDMT1 gene for infant genotypes. Relative risks ranged from 2.61 to 3.00, and the greatest risk was for infants with the AG on polymorphism rs10795459 (relative risk 3.0, 95\% confidence interval 1.63 to 5.51). Risks ranged from 6.81 to 9.00 for the homozygous alleles on the respective single nucleotide polymorphisms.

\section{Discussion}

In this population based study we found that common single nucleotide polymorphisms, related to glutathione and one-carbon metabolism, modified the risk of birth defects such that mothers with specific genotypes and periconceptual SSRI use had more than twice the risk of having an infant with an obstructive or conotruncal heart defect. Likewise, infants with maternal SSRI exposure and specific genotypes had 1.79 to 2.60 times the risk of the included heart defects. A subgroup analysis showed that two maternal and three infant single nucleotide polymorphisms, each within TRDMT1, were strongly associated with development of an obstructive heart defect. In contrast, we found no interaction among genotype, SSRI exposure, and risk of conotruncal heart defects. These findings provide insight into the genetic susceptibility of congenital heart defects to maternal SSRI use around pregnancy and provide support for our effect modification hypothesis.

\section{Strengths and limitations}

Strengths of our study include its large multi-ethnic population based sample size, verification of diagnoses, and standardization of classification of congenital 


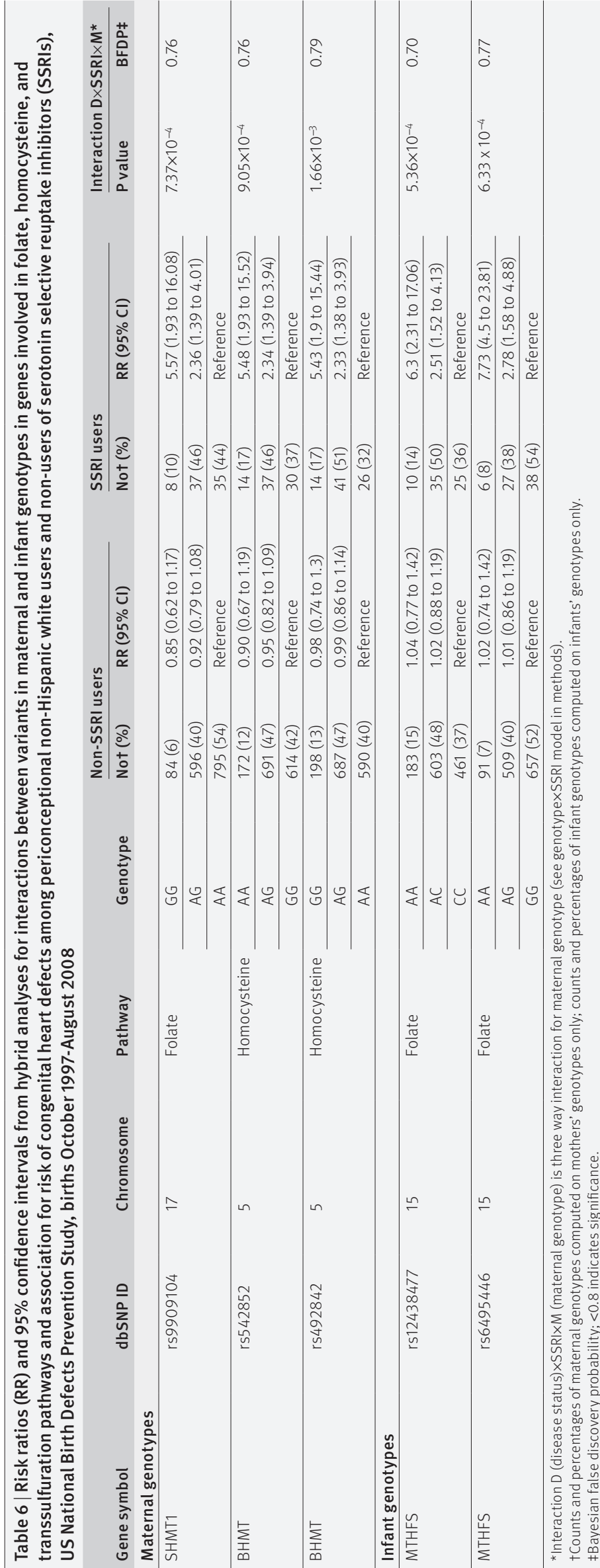

heart defects across study centers. Unlike many previous investigations of SSRI use and risk of congenital heart defects, our information on exposure was based on maternal self report, which is a better measure of drugs taken rather than drugs prescribed during the exposure window. Furthermore, the use of the log linear model for our analyses enabled us to assess the simultaneous effects of maternal and infant genotype on risk of congenital heart defects among SSRI users and non-users. This analytic approach also controls for possible population stratification of the infant's genotype.

Some potential limitations, however, should be considered. Information concerning periconceptional SSRI use could be subject to measurement error and recall bias as women were asked 12-24 months after delivery to report use. We also examined the effects of all SSRIs combined and did not assess the effects of specific SSRIs. Although we examined the use of periconceptional folic acid supplementation we did not assess dietary intake of folate and its role on the association between SSRI use and risk of congenital heart defects in our population. The DNA used in our study was obtained from self collected buccal cheek cell samples, which resulted in variable quality of samples. Although the hybrid design is the most appropriate method for analyzing our trio data, a current limitation of this statistical approach is inability to include potential confounders in the model. Despite our fairly large sample size, only a small number of women took SSRIs during the periconception period. Although the log linear model adjusts for potential confounding by population stratification, we assessed our results only among non-Hispanic white mothers because $85 \%$ of SSRI users fell into this ethnic group. Results from this homogenous subgroup were similar to those from the full sample, including significant associations for the maternal single nucleotide polymorphisms on SHMT and BHMT and infant single nucleotide polymorphisms on MTHFS (table 6).

\section{Comparison with previous studies}

We found no directly comparable studies when we searched PubMed for studies published in English before 2016 that investigated the association between maternal or infant genotype and risk of congenital heart defects among women taking SSRIs during pregnancy. We have therefore provided comparisons with the broader literature. An earlier study also using data from the NBDPS did not find a significantly increased risk of conotruncal defects (odds ratio 1.3, 95\% confidence interval 0.8 to 2.1) among women taking an SSRI during pregnancy. ${ }^{3276}$ A 2015 study using 1997-2009 data from the NBDPS, however, reported significant associations between maternal use of the SSRIs fluoxetine or paroxetine and atrial septal defects (1.8, 1.1 to 3.0) and right ventricular outflow tract obstruction defects (2.4, 1.4 to 3.9)..$^{76}$ An earlier case control study conducted in the US also reported similar findings. ${ }^{39}$ A large Norwegian study showed an increased risk of congenital heart defects among infants exposed to any SSRI during early pregnancy $(1.15,1.05$ to 1.26$)$ and reported a significant 
association between SSRI exposure and right ventricular outflow tract obstructions $(1.48,1.15$ to 1.89$) .{ }^{91} \mathrm{~A}$ sibling controlled analysis within the Norwegian study, however, did not find a significant association between SSRI exposure and congenital heart defects. In our study, over half of the women who took SSRIs were taking sertaline or fluoxetine, both of which show little evidence for increased risk of congenital heart defects in empiric studies or meta-analyses of epidemiologic studies, ${ }^{73536}$ yet we still observed an increased risk of such defects among women and infants with common allelic variants.

\section{Potential mechanisms}

Our findings highlighted single nucleotide polymorphisms related to one-carbon metabolism and the transsulfuration pathway. One-carbon metabolism encompasses both the folate and methionine/homocysteine cycles and is integral to cardiac development. ${ }^{92}$ It supports nutrient metabolism and other processes vital to a developing heart. It supplies methyl groups to DNA, RNA, and chromatin, allowing the body to maintain tight control over gene transcription during cardiogenesis. The transsulfuration pathway is another important component of one-carbon metabolism. One of its most important byproducts is glutathione, ${ }^{92-94}$ an antioxidant that helps the developing heart resist damage from reactive oxygen species and xenobiotic compounds. ${ }^{69} 95$ The single nucleotide polymorphisms reported in this study could serve as markers for nearby functional variants (a genetic variant that alters the function of the gene). Alternatively, they could directly affect protein expression and function. Most of the single nucleotide polymorphisms identified in the results introduce new splice sites and could alter protein function as a result (rs9909104, rs492842, rs542852, rs11511217, rs7294985, rs2038576, rs2273735, rs17464824, rs10904893). The remaining polymorphisms do not seem to directly impact protein function. Instead, they could be marking nearby functional variants.

There are several mechanisms that could account for the results. Variants in two genes, SHMT1 and MTHFS, within the folate pathway were associated with an increased risk of congenital heart defects among women with SSRI exposure during early pregnancy. Both genes encode proteins that catalyze the conversion of folate metabolites into 5,10-methylenetetrahydrofolate, a folate pathway intermediate that provides methyl groups for biosynthesis of thymidylate and purines. ${ }^{96}$ Neither SHMT1 nor MTHFS participate in the synthesis or turnover of 5-HT (serotonin), and it seems unlikely that these two single nucleotide polymorphisms interact directly with 5-HT during cardiac development. We hypothesize that variants within these genes sensitize an embryo to alterations in 5-HT, a critical cardiac signaling molecule. ${ }^{9798}$ SHMT1 and MTHFS are both vital to embryonic development, and defects in SHMT1 can impair hippocampal neurogenesis ${ }^{99}$ and cause neural tube defects in mouse models. ${ }^{100}$ The polymorphism identified in SHMT1 (rs9909104) is associated with increased risk of ovarian cancer, ${ }^{101}$ and a second polymorphisms (rs669340) within SHMT1 is associated with development of neural tube defect. ${ }^{102}$ Meanwhile, mice lacking the MTHFS gene do not survive past the embryonic stage, and mice with only one functional allele showed a 50\% reduction in de novo purine synthesis. ${ }^{103}$ MTHFS rs12438477 was associated with conotruncal heart defects in one of our previous studies. ${ }^{68}$ Our present study identified an association between rs12438477 within MTHFS and an increased risk of congenital heart defects among infants exposed to SSRIs in pregnancy.

Allelic variants in three genes involved in the homocysteine pathway-BHMT, GNMT, and TRDMT1-were also associated with increased risk of congenital heart defects in the presence of periconceptional SSRIs. BHMT facilitates homocysteine re-methylation into methionine. ${ }^{104}$ The enzyme encoded by GNMT is critical in regulating cellular concentration of S-adenosyl methionine (AdoMet). ${ }^{105}$ TRDMT1 (formerly DNMT2) encodes a methyltransferase that stabilizes aspartic acid and transfer RNA and supports protein synthesis. ${ }^{106}$ Deletion of BHMT in mice leads to major perturbations in choline, homocysteine, and AdoMet. In humans, polymorphisms in BHMT were associated with decreased circulating concentrations of the antioxidant glutathione. ${ }^{68}$ Excess homocysteine is thought to cause endothelial damage in adults ${ }^{107}$ and is associated with increased risk of congenital heart defects in newborns. ${ }^{10108109}$ Evidence from animal models suggests that homocysteine might increase risk of congenital heart defects either by increasing oxidative stress ${ }^{110}$ or by binding to N-methyl-D-aspartate (NMDA) receptors, resulting in abnormal cardiac neural crest cell migration and differentiation. ${ }^{111}$

We found three genes involved in the transsulfuration pathway-MGST1, MGMT, and GSTP-that were associated with an increased risk of congenital heart defects among women taking SSRIs. MGST1 is involved in "conjugation of glutathione to electrophiles and the reduction of lipid hydroperoxides" (RefSeq Accession NM_145792.2). This reaction is one of the mechanisms by which glutathione, a product of the transsulfuration pathway, protects intracellular membranes from oxidative stress. The GST gene family produces enzymes involved in detoxification by catalyzing the conjugation of many hydrophobic and electrophilic compounds with reduced glutathione. The GSTP1 gene is believed to catalyze the detoxification of xenobiotics (chemical compounds-as drugs, pesticides, or carcinogens-that are foreign to a living organism) $)^{112}$ and byproducts of oxidative stress; they could play a role in susceptibility to cancer and other diseases, as this gene is often upregulated in neoplastic cells (RefSeq Accession NM_000853.3).

Dysfunction in either the transsulfuration pathway or the homocysteine pathways can lead to an increased level of oxidative stress. ${ }^{110}$ Oxidative stress can in turn decrease the bioavailability of 5,6,7,8-tetrahydrobiopterin (BH4), ${ }^{113}$ a critical precursor for 5-HT (serotonin). Increased oxidative stress in the presence of 5-HT can 
also promote the formation of harmful free radicals, which could damage developing cardiac tissue. ${ }^{114} 115$ Although the teratogenic effects of SSRIs on the fetal heart are postulated to occur through interference of 5 -HT signaling during cardiogenesis, ${ }^{11}$ the specific role of the common variants and/or genes is poorly understood in these three metabolic pathways in the association between depression, metabolism of SSRIs, and increased risk of congenital heart defects. These genes, however, have previously been investigated for their role in risk of congenital heart defects. Hobbs and colleagues reported a 1.8 increased risk of congenital heart defects among obese women carrying the $742 \mathrm{G}>\mathrm{A}$ polymorphism in BHMT, ${ }^{116}$ and Mitchell and colleagues also showed a similar pattern of increased risk for left sided of congenital heart defects for the same polymorphism, though not significant. ${ }^{117} \mathrm{Li}$ and colleagues found significant main effects for different fetal polymorphisms in the MGMT and MTHFS genes. ${ }^{118} \mathrm{Zhu}$ and colleagues investigated rs9909104 on SHMT1 for its association with increased risk of congenital heart defects but found no association. ${ }^{119}$

These complex relations could partially explain the conflicting epidemiologic literature concerning the teratogenicity of SSRI use during the periconception period as studies that do show an association do not distinguish between pharmaceutical effects and the underlying effects of depression and its associated behaviors and conditions. Several investigators posited confounding by indication to explain the reported associations in the literature. ${ }^{4120}$ One large US epidemiologic study that restricted the study population to depressed women (as opposed to adjusting for depression) to account for potential confounding by indication and associated behaviors found no association between prenatal SSRI exposure and risk of congenital heart defects. ${ }^{4}$ A nationwide study in Denmark found an increased risk of such defects for women taking SSRIs during pregnancy and for women who stopped taking SSRIs six months before conception of the index pregnancy, ${ }^{92}$ which also supports the potential confounding effect of maternal illness. Although recent cohort studies conducted in the US ${ }^{4}$ and the UK ${ }^{121}$ reported significant associations between SSRI use (paroxetine) and congenital heart defects, the associations were not significant in fully adjusted models restricted to women with depression. We hypothesized that some women might have an increased genetic susceptibility to possible adverse effects of SSRIs on the developing heart. Polymorphisms in genes involved in folate metabolism are associated with increased risk of congenital heart defects ${ }^{6878116122-128}$ and depression. ${ }^{7071129}$ Thus, we postulate that some women who take SSRIs during cardiogenesis could be at higher risk if they have genetic polymorphisms in other folate metabolism related genes.

\section{Future directions and conclusions}

Our results provide initial evidence of a modifying effect of common maternal and infant variants in genes that encode for critical enzymes in the folate, homocysteine, and glutathione/transulfuration pathways on the association between maternal periconceptional SSRI use and risk of congenital heart defects in their offspring. Given the widespread use of SSRIs among women for various conditions, further exploration is warranted of the complex association between risk of congenital heart defects and folate supplementation, periconceptional SSRI use, and variants in folate, homocysteine, and glutathione/transsulfuration pathways among women with psychiatric illness.

We thank the families who participated in the National Birth Defects Prevention Study and made this research study possible. We also thank the Centers for Birth Defects Research and Prevention in California, Georgia, lowa, and Texas for generously contributing their DNA samples for these analyses and Laura Rakes for her tremendous assistance in preparing this manuscript.

Contributors: WNN, ZS, and DW designed the study. XT and ZH did the statistical analysis. SMacL developed the genotyping. All authors developed the manuscript. WNN is guarantor.

Funding: The study received funding from the Eunice Kennedy Shriver National Institute of Child Health and Human Development (\#5R01HD039054-12), the CDC National Center on Birth Defects and Developmental Disabilities (\#5U01DD000491-05), and the Arkansas Biosciences Institute. The contents of this manuscript are solely the responsibility of the authors and do not necessarily represent the official views of the Centers for Disease Control and Prevention. The study funders played no role in the study design; in the collection, analysis, and interpretation of data; in the writing of the report; or in the decision to submit the article for publication. The researchers are independent from the funders, and all authors, external and internal, had full access to all of the data (including statistical reports and tables) in the study and can take responsibility for the integrity of the data and the accuracy of the data analysis.

Competing interests: All authors have completed the ICMJE uniform disclosure form at www.icmje.org/coi_disclosure.pdf and declare: no financial relationships with any organizations that might have an interest in the submitted work in the previous three years; no other relationships or activities that could appear to have influenced the submitted work.

Ethical approval: This study was approved by the University of Arkansas for Medical Sciences institutional review board, and the National Birth Defects Prevention Study (NBDPS) was approved by the institutional review boards at the Centers for Disease Control and Prevention and all NBDPS institutions. All study participants provided written informed consent.

Data sharing: No additional data available.

Transparency: The lead author affirms that this manuscript is an honest, accurate, and transparent account of the study being reported; that no important aspects of the study have been omitted; and that any discrepancies from the study as planned (and, if relevant, registered) have been explained.

Grigoriadis S, Robinson GE. Gender issues in depression. Ann Clin Psychiatry 2007;19:247-55. doi:10.1080/10401230701653294

2 Evans J, Heron J, Francomb H, Oke S, Golding J. Cohort study of depressed mood during pregnancy and after childbirth. $B M$ 2001;323:257-60. doi:10.1136/bmj.323.7307.257.

3 Mitchell AA, Gilboa SM, Werler MM, Kelley KE, Louik C, HernándezDíaz S. National Birth Defects Prevention Study. Medication use during pregnancy, with particular focus on prescription drugs: 1976-2008. Am J Obstet Gynecol 2011;205:51.e1-8. doi:10.1016/j. ajog.2011.02.029.

4 Huybrechts KF, Palmsten K, Avorn J, et al. Antidepressant use in pregnancy and the risk of cardiac defects. N Engl/ Med 2014:370:2397-407. doi:10.1056/NEJMoa1312828.

. Huybrechts KF, Palmsten K, Mogun $\mathrm{H}$, et al. National trends in antidepressant medication treatment among publicly insured pregnant women. Gen Hosp Psychiatry 2013;35:265-71 doi:10.1016/j.genhosppsych.2012.12.010.

6 Alwan S, Reefhuis J, Rasmussen SA, Friedman JM. National Birth Defects Prevention Study. Patterns of antidepressant medication use among pregnant women in a United States population. J Clin Pharmacol 2011:51:264-70. doi:10.1177/0091270010373928. Yonkers KA, Blackwell KA, Glover J, Forray A. Antidepressant use in pregnant and postpartum women. Annu Rev Clin Psychol 2014;10:369-92. doi:10.1146/annurev-clinpsy-032813-153626. 
8 Miller E, Hare JW, Cloherty JP, et al. Elevated maternal hemoglobin A1C in early pregnancy and major congenital anomalies in infants of diabetic mothers. N Engl / Med 1981:304:1331-4. doi:10.1056/ NEIM198105283042204.

9 Sadler TW, Rasmussen SA. Examining the evidence for vascular pathogenesis of selected birth defects. Am I Med Genet $A$ 2010;152A:2426-36. doi:10.1002/ajmg.a.33636.

10 Miller AL. The methylation, neurotransmitter, and antioxidant connections between folate and depression. Altern Med Rev 2008:13:216-26.

11 Sadler TW. Selective serotonin reuptake inhibitors (SSRIS) and heart defects: potential mechanisms for the observed associations. Reprod Toxicol 2011;32:484-9. doi:10.1016/j.reprotox.2011.09.004

12 Papakostas GI, Shelton RC, Zajecka JM, et al. L-methylfolate as adjunctive therapy for SSRI-resistant major depression: results of two randomized, double-blind, parallel-sequential trials. Am J Psychiatry 2012;169:1267-74. doi:10.1176/appi.ajp.2012.11071114

13 Lynberg MC, McClearn AB, Edmonds LD, Khoury MJ. Mortality among infants with birth defects, metropolitan Atlanta, 1983-1989. Teratology 1991;43:449.

14 Druschel C. Hughes JP, Olsen C. Mortality among infants with congenital malformations, New York State, 1983 to 1988. Public Health Rep 1996;111:359-65.

15 Lee K, Khoshnood B, Chen L, Wall SN, Cromie WJ, Mittendorf RL. Infant mortality from congenital malformations in the United States, 1970-1997. Obstet Gynecol 2001;98:620-7.

16 Nembhard WN, Waller DK, Sever LE, Canfield MA. Patterns of first-year survival among infants with selected congenital anomalies in Texas, 1995-1997. Teratology 2001;64:267-75. doi:10.1002/tera.1073.

17 Lloyd-Jones D, Adams RJ, Brown TM, et al. American Heart Association Statistics Committee and Stroke Statistics Subcommittee. Executive summary: heart disease and stroke statistics--2010 update: a report from the American Heart Association. Circulation 2010;121:948-54. doi:10.1161/CIRCULATIONAHA.109.192666.

18 Colvin L, Slack-Smith L, Stanley FJ, Bower C. Dispensing patterns and pregnancy outcomes for women dispensed selective serotonin reuptake inhibitors in pregnancy. Birth Defects Res A Clin Mol Teratol 2011;91:142-52. doi:10.1002/bdra.20773.

19 Kornum JB, Nielsen RB, Pedersen L, Mortensen PB, Nørgaard M. Use of selective serotonin-reuptake inhibitors during early pregnancy and risk of congenital malformations: updated analysis. Clin Epidemiol 2010:2:29-36 doi:10.2147/CLEPS9256.

20 Nikfar S, Rahimi R, Hendoiee N, Abdollahi M. Increasing the risk of spontaneous abortion and major malformations in newborns following use of serotonin reuptake inhibitors during pregnancy: A systematic review and updated meta-analysis. Daru 2012;20:75 doi:10.1186/2008-2231-20-75.

21 Knudsen TM, Hansen AV, Garne E, Andersen AM. Increased risk of severe congenital heart defects in offspring exposed to selective serotonin-reuptake inhibitors in early pregnancy--an epidemiological study using validated EUROCAT data. BMC Pregnancy Childbirth 2014:14:333. doi:10.1186/1471-2393-14-333.

22 Polen KN, Rasmussen SA, Riehle-Colarusso T, Reefhuis J. National Birth Defects Prevention Study. Association between reported venlafaxine use in early pregnancy and birth defects, national birth defects prevention study, 1997-2007. Birth Defects Res A Clin Mol Teratol 2013;97:28-35. doi:10.1002/bdra.23096

23 Davis RL, Rubanowice D, McPhillips H, et al. HMO Research Network Center for Education, Research in Therapeutics. Risks of congenital malformations and perinatal events among infants exposed to antidepressant medications during pregnancy. Pharmacoepidemiol Drug Saf2007;16:1086-94. doi:10.1002/pds.1462.

24 Pedersen LH, Henriksen TB, Vestergaard M, Olsen J, Bech BH. Selective serotonin reuptake inhibitors in pregnancy and congenital malformations: population based cohort study. BMJ 2009;339:b3569. doi:10.1136/bmi.b3569.

25 Reis M, Källén B. Delivery outcome after maternal use of antidepressant drugs in pregnancy: an update using Swedish data. Psychol Med 2010;40:1723-33. doi:10.1017/S0033291709992194.

26 Malm H, Artama M, Gissler M, Ritvanen A. Selective serotonin reuptake inhibitors and risk for major congenital anomalies. Obstet Gynecol 2011;118:111-20. doi:10.1097/AOG.0b013e318220edcc

27 Kulin NA, Pastuszak A, Sage SR, et al. Pregnancy outcome following maternal use of the new selective serotonin reuptake inhibitors: a prospective controlled multicenter study. JAMA 1998;279:609-10. doi:10.1001/jama.279.8.609.

28 Simon GE, Cunningham ML, Davis RL. Outcomes of prenatal antidepressant exposure. Am J Psychiatry 2002;159:2055-61. doi:10.1176/appi.ajp.159.12.2055

29 Sivojelezova A, Shuhaiber S, Sarkissian L, Einarson A, Koren G. Citalopram use in pregnancy: prospective comparative evaluation of pregnancy and fetal outcome. Am J Obstet Gynecol 2005;193:2004-9. doi:10.1016/j.ajog.2005.05.012.

30 Wisner KL, Sit DK, Hanusa BH, et al. Major depression and antidepressant treatment: impact on pregnancy and neonatal outcomes. Am J Psychiatry 2009;166:557-66. doi:10.1176/appi. ajp.2008.08081170.
31 Einarson A, Fatoye B, Sarkar M, et al. Pregnancy outcome following gestational exposure to venlafaxine: a multicenter prospective controlled study. Am J Psychiatry 2001;158:1728-30. doi:10.1176/ appi.ajp.158.10.1728

32 Alwan S, Reefhuis J, Rasmussen SA, Olney RS, Friedman JM. National Birth Defects Prevention Study. Use of selective serotonin-reuptake inhibitors in pregnancy and the risk of birth defects. N Engl J Med 2007;356:2684-92. doi:10.1056/NEJMoa066584.

33 Källén K, Olausson PO. Neonatal mortality for low-risk women by method of delivery. Birth 2007:34:99-100, author reply 101-2. doi:10.1111/j.1523-536X.2006.00155_1.X.

34 Wurst KE, Poole C, Ephross SA, Olshan AF. First trimester paroxetine use and the prevalence of congenital, specifically cardiac, defects: a meta-analysis of epidemiological studies. Birth Defects Res A Clin Mol Teratol 2010;88:159-70. doi:10.1002/bdra.20627.

35 Grigoriadis S, VonderPorten EH, Mamisashvili L, et al. Antidepressant exposure during pregnancy and congenital malformations: is there an association? A systematic review and meta-analysis of the best evidence. J Clin Psychiatry 2013;74:e293-308. doi:10.4088/ JCP.12r07966.

36 Myles N, Newall H, Ward H, Large M. Systematic meta-analysis of individual selective serotonin reuptake inhibitor medications and congenital malformations. Aust N ZJ Psychiatry 2013;47:1002-12. doi:10.1177/0004867413492219.

37 Cole JA, Ephross SA, Cosmatos IS, Walker AM. Paroxetine in the first trimester and the prevalence of congenital malformations. Pharmacoepidemiol Drug Saf 2007;16:1075-85. doi:10.1002/ pds.1463.

38 Diav-Citrin O, Shechtman S, Weinbaum D, et al. Paroxetine and fluoxetine in pregnancy: a prospective, multicentre, controlled, observational study. Br J Clin Pharmacol 2008;66:695-705. doi:10.1111/j.1365-2125.2008.03261.x

39 Louik C, Lin AE, Werler MM, Hernández-Díaz S, Mitchell AA. First-trimester use of selective serotonin-reuptake inhibitors and the risk of birth defects. N Engl J Med 2007;356:2675-83. doi:10.1056/ NEJMoa067407.

40 Hayes RM, Wu P, Shelton RC, et al. Maternal antidepressant use and adverse outcomes: a cohort study of 228,876 pregnancies. Am J Obstet Gynecol 2012;207:49.e1-9. doi:10.1016/j.ajog.2012.04.028.

41 Malik S, Cleves MA, Honein MA, et al. National Birth Defects Prevention Study. Maternal smoking and congenital heart defects. Pediatrics 2008;121:e810-6. doi:10.1542/peds.2007-1519.

42 Grewal J, Carmichael SL, Ma C, Lammer EJ, Shaw GM. Maternal periconceptional smoking and alcohol consumption and risk for select congenital anomalies. Birth Defects Res A Clin Mol Terato 2008;82:519-26. doi:10.1002/bdra.20461.

43 Hackshaw A, Rodeck C, Boniface S. Maternal smoking in pregnancy and birth defects: a systematic review based on 173687 malformed cases and 11.7 million controls. Hum Reprod Update 2011;17:589604. doi:10.1093/humupd/dmr022.

44 Patel SS, Burns TL, Botto LD, et al National Birth Defects Prevention Study. Analysis of selected maternal exposures and non-syndromic atrioventricular septal defects in the National Birth Defects Prevention Study, 1997-2005. Am J Med Genet A 2012;158A:2447-55. doi:10.1002/ajmg.a.35555.

45 Watkins ML, Botto LD. Maternal prepregnancy weight and congenital heart defects in offspring. Epidemiology 2001;12:439-46. doi:10.1097/00001648-200107000-00014

46 Gilboa SM, Correa A, Botto LD, et al. National Birth Defects Prevention Study. Association between prepregnancy body mass index and congenital heart defects. Am J Obstet Gynecol 2010;202:51.e1-10. doi:10.1016/i.ajog.2009.08.005.

47 Blomberg MI, Källén B. Maternal obesity and morbid obesity: the risk for birth defects in the offspring. Birth Defects Res A Clin Mol Teratol 2010:88:35-40. doi:10.1002/bdra.20620.

48 Towner D, Kjos SL, Leung B, et al. Congenital malformations in pregnancies complicated by NIDDM. Diabetes Care 1995;18:1446-51 doi:10.2337/diacare.18.11.1446.

49 Caton AR, Bell EM, Druschel CM, et al. National Birth Defects Prevention Study. Antihypertensive medication use during pregnancy and the risk of cardiovascular malformations. Hypertension 2009:54:63-70. doi:10.1161/HYPERTENSIONAHA.109.129098.

50 Lennestål R, Otterblad Olausson P, Källén B. Maternal use of antihypertensive drugs in early pregnancy and delivery outcome, notably the presence of congenital heart defects in the infants. Eur I Clin Pharmacol 2009:65:615-25. doi:10.1007/s00228-009-0620-0.

51 Botto LD, Khoury MJ, Mulinare J, Erickson JD. Periconceptional multivitamin use and the occurrence of conotruncal heart defects: results from a population-based, case-control study. Pediatrics 1996;98:911-7.

52 Czeizel AE. Periconceptional folic acid containing multivitamin supplementation. EurJ Obstet Gynecol Reprod Biol 1998;78:151-61. doi:10.1016/S0301-2115(98)00061-X

53 Wenstrom KD, Johanning GL, Johnston KE, DuBard M. Association of the C677T methylenetetrahydrofolate reductase mutation and elevated homocysteine levels with congenital cardiac malformations. Am J Obstet Gynecol 2001:184:806-17. doi:10.1067/mob.2001.113845. 
54 Hobbs CA, Cleves MA, Melnyk S, Zhao W, James SJ. Congenital heart defects and abnormal maternal biomarkers of methionine and homocysteine metabolism. Am / Clin Nutr 2005;81:147-53.

55 Verkleij-Hagoort AC, Verlinde M, Ursem NT, et al. Maternal hyperhomocysteinaemia is a risk factor for congenital heart disease. BJOG 2006;113:1412-8. doi:10.1111/j.1471-0528.2006.01109.x.

56 Levitt AJ, Joffe RT. Folate, B12, and life course of depressive illness. Biol Psychiatry 1989;25:867-72. doi:10.1016/0006-3223(89)90266-7.

57 Tolmunen T, Voutilainen S, Hintikka J, et al. Dietary folate and depressive symptoms are associated in middle-aged Finnish men.J Nutr 2003;133:3233-6.

58 Papakostas GI, Petersen T, Mischoulon D, et al. Serum folate, vitamin B12, and homocysteine in major depressive disorder, Part 2: predictors of relapse during the continuation phase of pharmacotherapy. J Clin Psychiatry 2004;65:1096-8. doi:10.4088/JCP.v65n0811

59 Beydoun MA, Shroff MR, Beydoun HA, Zonderman AB. Serum folate, vitamin B-12, and homocysteine and their association with depressive symptoms among U.S. adults. Psychosom Med 2010;72:862-73. doi:10.1097/PSY.0b013e3181f61863.

60 Czeizel AE, Dudás I. Prevention of the first occurrence of neural-tube defects by periconceptional vitamin supplementation. N Engl / Med 1992;327:1832-5. doi:10.1056/NEJM199212243272602.

61 Botto LD, Mulinare J, Erickson JD. Do multivitamin or folic acid supplements reduce the risk for congenital heart defects? Evidence and gaps. Am J Med Genet A 2003;121A:95-101. doi:10.1002/ ajmg.a.20132.

62 Oster ME, Riehle-Colarusso T, Simeone RM, et al. Public health science agenda for congenital heart defects: report from a Centers for Disease Control and Prevention experts meeting. I Am Heart Assoc 2013:2:e000256. doi:10.1161/JAHA.113.000256.

63 Czeizel AE, Dudás I, Vereczkey A, Bánhidy F. Folate deficiency and folic acid supplementation: the prevention of neural-tube defects and congenital heart defects. Nutrients 2013;5:4760-75. doi:10.3390/ nu5114760.

64 Fava M. Augmenting antidepressants with folate: a clinical perspective. J Clin Psychiatry 2007;68(Suppl 10):4-7.

65 Stahl SM. Novel therapeutics for depression: L-methylfolate as a trimonoamine modulator and antidepressant-augmenting agent. CNS Spectr 2007;12:739-44. doi:10.1017/S1092852900015418.

66 Shelton RC, Sloan Manning J, Barrentine LW, Tipa EV. Assessing Effects of l-Methylfolate in Depression Management: Results of a Real-World Patient Experience Trial. Prim Care Companion CNS Disord 2013;15:PCC.13m01520. doi:10.4088/PCC.13m01520.

67 Junker $\mathrm{R}$, KotthoffS, Vielhaber $\mathrm{H}$, et al. Infant methylenetetrahydrofolate reductase 677TT genotype is a risk factor for congenital heart disease. Cardiovasc Res 2001;51:251-4 doi:10.1016/S0008-6363(01)00286-3.

68 Hobbs CA, Cleves MA, Macleod SL, et al. National Birth Defects Prevention Study. Conotruncal heart defects and common variants in maternal and fetal genes in folate, homocysteine, and transsulfuration pathways. Birth Defects Res A Clin Mol Teratol 2014:100:116-26 doi:10.1002/bdra. 23225

69 Tang X, Cleves MA, Nick TG, et al. National Birth Defects Prevention Study Obstructive heart defects associated with candidate genes, maternal obesity, and folic acid supplementation. Am / Med Genet $A$ 2015;167:1231-42. doi:10.1002/ajmg.a.36867.

70 Kelly CB, McDonnell AP, Johnston TG, et al. The MTHFR C677T polymorphism is associated with depressive episodes in patients from Northern Ireland. J Psychopharmacol 2004;18:567-71. doi:10.1177/026988110401800415

71 Gilbody S, Lewis S, Lightfoot T. Methylenetetrahydrofolate reductase (MTHFR) genetic polymorphisms and psychiatric disorders: a HuGE review. Am J Epidemiol 2007;165:1-13. doi:10.1093/aje/kwj347.

72 Wu YL, Ding XX, Sun YH, et al. Association between MTHFR C677T polymorphism and depression: An updated meta-analysis of 26 studies. Prog Neuropsychopharmacol Biol Psychiatry 2013;46:78-85 doi:10.1016/j.pnpbp.2013.06.015.

73 Yoon PW, Rasmussen SA, Lynberg MC, et al. The National Birth Defects Prevention Study. Public Health Rep 2001;116(Suppl 1):32-40. doi:10.1093/phr/116.S1.32

74 Reefhuis J, Gilboa SM, Anderka M, et al. National Birth Defects Prevention Study. The National Birth Defects Prevention Study: A review of the methods. Birth Defects Res A Clin Mol Teratol 2015;103:656-69. doi:10.1002/bdra.23384.

75 Botto LD, Lin AE, Riehle-Colarusso T, Malik S, Correa A. National Birth Defects Prevention Study. Seeking causes: Classifying and evaluating congenital heart defects in etiologic studies. Birth Defects Res A Clin Mol Teratol 2007;79:714-27. doi:10.1002/bdra.20403.

76 Reefhuis J, Devine O, Friedman JM, Louik C, Honein MA. National Birth Defects Prevention Study. Specific SSRIs and birth defects: Bayesian analysis to interpret new data in the context of previous reports. $B M$ 2015;351:h3190. doi:10.1136/bmj.h3190.

77 Rasmussen SA, Lammer El, Shaw GM et al. National Birth Defects Prevention Study. Integration of DNA sample collection into a multi-site birth defects case-control study. Teratology 2002;66:17784. doi:10.1002/tera.10086.
78 Chowdhury S, Hobbs CA, MacLeod SL, et al. Associations between maternal genotypes and metabolites implicated in congenital heart defects. Mol Genet Metab 2012;107:596-604. doi:10.1016/j. ymgme.2012.09.022

79 Fan JB, Gunderson KL, Bibikova M, et al. Illumina universal bead arrays. Methods Enzymol 2006;410:57-73. doi:10.1016/ S0076-6879(06)10003-8.

80 Cunningham JM, Sellers TA, Schildkraut JM, et al. Performance of amplified DNA in an Illumina GoldenGate BeadArray assay. Cancer Epidemiol Biomarkers Prev 2008:17:1781-9 doi:10.1158/1055-9965. EPI-07-2849.

81 Erickson SW, Calloway JC. SNPMClust: Bivariate Gaussian Genotype Clustering and Calling for Illumina Microarrays. J Stat Softwdoi:10.18637/jss.v071.c02

82 Weinberg CR, Umbach DM. A hybrid design for studying genetic influences on risk of diseases with onset early in life. Am J Hum Genet 2005:77:627-36 doi:10.1086/496900.

83 Wakefield J. A Bayesian measure of the probability of false discovery in genetic epidemiology studies. Am J Hum Genet 2007;81:208-27. doi:10.1086/519024

84 Oh SS, Chang SC, Cai L, et al. Single nucleotide polymorphisms of 8 inflammation-related genes and their associations with smoking related cancers. Int J Cancer 2010;127:2169-82. doi:10.1002/ ijc. 25214

85 Liu JZ, Tozzi F, Waterworth DM, et al. Wellcome Trust Case Control Consortium. Meta-analysis and imputation refines the association of 15 q25 with smoking quantity. Nat Genet 2010;42:436-40. doi: $10.1038 /$ ng.572

86 Park SL, Bastani D, Goldstein BY, et al. Associations between NBS1 polymorphisms, haplotypes and smoking-related cancers. Carcinogenesis 2010;31:1264-71. doi:10.1093/carcin/bgq096.

87 Vermunt JK. LEM: A General Program for the Analysis of Categorical Data.Department of Methodology and Statistics, Tilburg University, 1997.

88 Dempster AP, Laird NM, Rubin DB.Maximum likelihood estimation from incomplete data via the EM algorithm. J R Stat Soc 1977;B(39):1-38.

89 Vermunt JK. Log-linear models for event histories. Sage Publications, 1997.

90 Vermunt JK. Log-linear event history analysis: a general approach with missing data, unobserved heterogeneity, and latent variables. Tilburg University Press, 1996.

91 Furu K, Kieler H, Haglund B, et al. Selective serotonin reuptake inhibitors and venlafaxine in early pregnancy and risk of birth defects: population based cohort study and sibling design. BMJ 2015;350:h1798. doi:10.1136/bmj.h1798.

92 Locasale JW. Serine, glycine and one-carbon units: cancer metabolism in full circle. Nat Rev Cancer 2013;13:572-83. doi:10.1038/nrc3557.

93 Wu G, Bazer FW, Cudd TA, Meininger CJ, Spencer TE. Maternal nutrition and fetal development. J Nutr 2004;134:2169-72

94 Kalhan SC, Marczewski SE. Methionine, homocysteine, one carbon metabolism and fetal growth. Rev Endocr Metab Disord 2012;13:10919. doi:10.1007/s11154-012-9215-7.

95 Dennery PA. Effects of oxidative stress on embryonic development Birth Defects Res CEmbryo Today 2007;81:155-62. doi:10.1002/ bdrc 20098.

96 Hardy LW, Finer-Moore JS, Montfort WR, Jones MO, Santi DV, Stroud RM. Atomic structure of thymidylate synthase: target for rational drug design. Science 1987;235:448-55. doi:10.1126/science.3099389.

97 Ori M, De Lucchini S, Marras G, Nardi I. Unraveling new roles for serotonin receptor 2B in development: key findings from Xenopus. Int J Dev Biol 2013;57:707-14. doi:10.1387/ijdb.130204mo.

98 Vandenberg LN, Lemire JM, Levin M. Serotonin has early, ciliaindependent roles in Xenopus left-right patterning. Dis Model Mech 2013;6:261-8. doi:10.1242/dmm.010256.

99 Abarinov EV, Beaudin AE, Field MS, et al. Disruption of shmt1 impairs hippocampal neurogenesis and mnemonic function in mice. J Nutr 2013;143:1028-35. doi:10.3945/jn.113.174417.

100 Beaudin AE, Abarinov EV, Noden DM, et al. Shmt1 and de novo thymidylate biosynthesis underlie folate-responsive neural tube defects in mice. Am J Clin Nutr 2011;93:789-98. doi:10.3945/ ajcn.110.002766.

101 Kelemen LE, Sellers TA, Schildkraut IM, et al. Genetic variation in the one-carbon transfer pathway and ovarian cancer risk. Cancer Res 2008;68:2498-506. doi:10.1158/0008-5472.CAN-07-5165.

102 Etheredge AJ, Finnell RH, Carmichael SL, et al. Maternal and infant gene-folate interactions and the risk of neural tube defects. Am J Med GenetA 2012;158A:2439-46. doi:10.1002/ajmg.a.35552.

103 Field MS, Anderson DD, Stover PJ. Mthfs is an Essential Gene in Mice and a Component of the Purinosome. Front Genet 2011;2:36. doi:10.3389/fgene.2011.00036.

104 Heil SG, Lievers KJ, Boers GH, et al. Betaine-homocysteine methyltransferase (BHMT): genomic sequencing and relevance to hyperhomocysteinemia and vascular disease in humans. Mol Genet Metab 2000;71:511-9. doi:10.1006/mgme.2000.3078.

105 Grillo MA, Colombatto S. S-adenosylmethionine and its products. Amino Acids 2008:34:187-93. doi:10.1007/s00726-007-0500-9. 
106 Tuorto F, Liebers R, Musch T, et al. RNA cytosine methylation by Dnmt2 and NSun2 promotes tRNA stability and protein synthesis. Nat Struct Mol Biol 2012:19.900-5. doi:10.1038/nsmb.2357.

107 Castro R, Rivera I, Blom HJ, Jakobs C, Tavares de Almeida I. Homocysteine metabolism, hyperhomocysteinaemia and vascular disease: an overview. J Inherit Metab Dis 2006;29:3-20. doi:10.1007/ s10545-006-0106-5.

108 Hobbs CA, Cleves MA, Zhao W, Melnyk S, James SJ. Congenital heart defects and maternal biomarkers of oxidative stress. Am J Clin Nutr 2005;82:598-604

109 Kapusta L, Haagmans ML, Steegers EA, Cuypers MH, Blom HJ, Eskes TK. Congenital heart defects and maternal derangement of homocysteine metabolism. J Pediatr 1999;135:773-4. doi:10.1016 S0022-3476(99)70102-2.

110 Tyagi N, Sedoris KC, Steed M, Ovechkin AV, Moshal KS, Tyagi SC. Mechanisms of homocysteine-induced oxidative stress. Am J Physiol Heart Circ Physiol 2005;289:H2649-56. doi:10.1152/ajpheart.00548.2005.

111 Stoller JZ, Epstein JA. Cardiac neural crest. Semin Cell Dev Biol 2005;16:704-15. doi:10.1016/j.semcdb.2005.06.004.

112 Miriam-Webster. Medical Dictionary. 2016 http://www.merriamwebster.com/dictionary/xenobiotic

113 Crabtree MJ, Tatham AL, Hale AB, Alp NJ, Channon KM. Critical role for tetrahydrobiopterin recycling by dihydrofolate reductase in regulation of endothelial nitric-oxide synthase coupling: relative importance of the de novo biopterin synthesis versus salvage pathways. J Biol Chem 2009;284:28128-36. doi:10.1074/jbc.M109.041483.

114 Maker HS, Weiss C, Silides DJ, Cohen G. Coupling of dopamine oxidation (monoamine oxidase activity) to glutathione oxidation via the generation of hydrogen peroxide in rat brain homogenates. J Neurochem 1981;36:589-93. doi:10.1111/j.1471-4159.1981.tb01631.x.

115 Chapman AL, Mocatta TJ, Shiva S, et al. Ceruloplasmin is an endogenous inhibitor of myeloperoxidase. J Biol Chem 2013;288:6465-77. doi:10.1074/jbc.M112.418970.

116 Hobbs CA Cleves MA, Karim MA, Zhao W, MacLeod SL Maternal folaterelated gene environment interactions and congenital heart defects. Obstet Gynecol 2010;116:316-22. doi:10.1097/AOG.0b013e3181e80979.

117 Mitchell LE, Long J, Garbarini J, Paluru P, Goldmuntz E. Variants of folate metabolism genes and risk of left-sided cardiac defects. Birth Defects Res A Clin Mol Teratol 2010;88:48-53. doi:10.1002/bdra.20622.

118 Li M, Cleves MA, Mallick H, et al. National Birth Defect Prevention Study. A genetic association study detects haplotypes associated with obstructive heart defects. Hum Genet 2014;133:1127-38 doi:10.1007/s00439-014-1453-1.
119 Zhu H, Yang W, Shaw N, et al. Thymidylate synthase polymorphisms and risk of conotruncal heart defects. Am J Med Genet $A$ 2012:158A:2194-203 doi:10.1002/ajmg.a.35310.

120 Jimenez-Solem E, Andersen JT, Petersen M, et al. Exposure to selective serotonin reuptake inhibitors and the risk of congenital malformations: a nationwide cohort study. BMJ Open 2012;2:e001148. doi:10.1136/bmjopen-2012-001148.

121 Ban L, Gibson JE, West J, et al. Maternal depression, antidepressant prescriptions, and congenital anomaly risk in offspring: a populationbased cohort study. BJOG 2014:121:1471-81. doi:10.1111/1471-0528.12682

122 Mamasoula C, Prentice RR, Pierscionek T, et al. Association between C677T polymorphism of methylene tetrahydrofolate reductase and congenital heart disease: meta-analysis of 7697 cases and 13,125 controls. Circ Cardiovasc Genet 2013;6:347-53. doi:10.1161/ CIRCGENETICS.113.000191.

123 Wang B, Liu M, Yan W, et al. Association of SNPs in genes involved in folate metabolism with the risk of congenital heart disease. J Matern Fetal Neonatal Med 2013;26:1768-77. doi:10.3109/14767058.2013.799648.

124 Wang W, Wang Y, Gong F, Zhu W, Fu S. MTHFR C677T polymorphism and risk of congenital heart defects: evidence from 29 case-control and TDT studies. PLoS One 2013;8:e58041. doi:10.1371/journal. pone.0058041.

125 Zhu H, Yang W, Lu W, et al. Gene variants in the folate-mediated one-carbon metabolism (FOCM) pathway as risk factors for conotruncal heart defects. Am J Med Genet A 2012;158A:1124-34. doi:10.1002/ajmg.a.35313

126 Christensen KE, Zada YF, Rohlicek CV, et al. Risk of congenital heart defects is influenced by genetic variation in folate metabolism. Cardiol Young 2013;23:89-98. doi:10.1017/S1047951112000431.

127 Long J, Lupo PJ, Goldmuntz E, Mitchell LE. Evaluation of heterogeneity in the association between congenital heart defects and variants of folate metabolism genes: conotruncal and left-sided cardiac defects. Birth Defects Res A Clin Mol Teratol 2011;91:879-84. doi:10.1002/ bdra.22849.

128 Nie Y, Gu H, Gong J, et al. Methylenetetrahydrofolate reductase C677T polymorphism and congenital heart disease: a meta-analysis. Clin Chem Lab Med 2011;49:2101-8. doi:10.1515/CCLM.2011.673.

129 Wu X, Luke A, Rieder M, et al. An association study of angiotensinogen polymorphisms with serum level and hypertension in an AfricanAmerican population. J Hypertens 2003;21:1847-52. doi:10.1097/00004872-200310000-00011. 